\title{
A Unique Hybrid Problem-Based Learning Model: Prospective Teacher Education and Development
}

\author{
Lorenzo Cherubini \\ Department of Teacher Education, Brock University, Ontario, Canada \\ Email: lorenzo.cherubini@brocku.ca
}

\begin{abstract}
Problem-Based Learning is understood as a student-centred approach to teaching and learning that complements psychological and social-constructivist learning models and theories. The literature points to the fact that PBL, as a case-based platform, is highly applicable to teacher education and professional development. Social-constructivist learning invites prospective teachers to participate thoughtfully in inquiry-based problems and analysis that have genuine implications on student and classroom issues. This paper, therefore, discusses a unique PBL model used in a professional teacher education program in a mid-sized university in Ontario, Canada. The combination of case-study, on-line communication, and the focus on students' metacognitive skills and processes increases students' control of their learning and engages them in meaningful and functional activities. The unique PBL model is a process of inquiry that creates spaces for prospective teachers to investigate, discuss, and negotiate the multiple and pertinent complexities and perspectives related to teachers' practice.
\end{abstract}

Keywords: problem-based learning, teacher education, prospective teacher learning and development.

\section{Introduction}

While its origins are in the health field (Barrows, 1996), the implementation of Problem-Based Learning (PBL) is currently far more widespread and considered among the most effective instructional strategies (Hung, 2009). PBL is understood as a student-centred approach to teaching and learning that complements psychological and social-constructivist learning models and theories (Anderson, 2005; Pourshafie \& Murray-Harvey, 2013). Providing structured opportunities for learners to co-construct meaning contributes significantly to student engagement (Cherubini 2009; Ice et al., 2011). The literature points to the fact that PBL, as a case-based platform, is highly applicable to teacher education and professional development (Pang, 2011; Steele, 2008). Moreover, such student-driven instructional strategies are a positive response to teacher education programming that is often criticized for what has been described as its sometimes-frivolous curriculum and disjointed perspectives of theory and practice (Borko et al., 2000; Forzani, 2009). Instead, social-constructivist learning invites prospective teachers to participate thoughtfully in inquiry-based problems and analysis that have genuine implications on student and classroom issues (Santagata \& Guarino, 2011). As Shulman and Wilson (2004) state, inquiry-based learning "is a combination of the passionate embrace of understanding of general simplifications of facts and ideas along with the development of critical, skeptical attitudes" (p. 401).

This paper, therefore, discusses a unique PBL model used in a professional teacher education program in a mid-sized university in Ontario, Canada. The model considers inquiry as the catalyst for student learning. While some of the procedures in this model are similar to those used in medical and law schools, the combination of case-study, on-line communication, and the focus on students' metacognitive skills and processes increases students' control of their learning and engages them in meaningful and functional activities. Through a structured and planned sequence of activities and small-group discussion, prospective teachers participate actively in the process of their own learning. The dilemma-based case studies force prospective teachers to account for misunderstandings, seek direction on elements of the case they may find ambiguous, and tailor their inquiries more precisely to the facts and details of the dilemma-based predicament. It is noteworthy that the course in which the PBL model is implemented 
includes less lecture and elaborate instruction; however, more significant is the fact that the model involves the students in thoughtfully and actively processing the complexities of the case-based dilemmas. Ultimately, as will be discussed in the paper, the unique PBL model is a process of inquiry that creates spaces for prospective teachers to investigate, discuss, and negotiate the multiple and pertinent complexities and perspectives related to teachers' practice.

\section{Literature Review}

In the original Problem Based Learning model developed by Burrows (1996), problems were organized thematically for learning and required students to use problem-solving skills to self-direct their own learning (see also, Goodnough, 2005). The literature on the background of PBL is quite vast (Barrett, 2010; Henderson, 2016). While PBL is typically considered a form of case-based methods of instruction, unlike in case studies the problem is the centre of learning for PBL instruction (McPhee, 2002). In PBL classrooms, collaborative learning is required to examine the multifaceted case-dilemmas. Prospective teachers are required to identify their learning needs, investigate multiple perspectives, consult with the relevant research, communicate effectively with their peer-based tutorial group, and arrive at a final reflection (Bridges, 2019; Cherubini, 2017a; Filipenko \& Naslund, 2016). PBL aims to foster students' ability to reason in an independent but collaborative learning environment and promote the production and utilization of knowledge that prospective teachers can apply directly to actual professional practices (Grigg \& Lewis, 2018). The process of engaging in PBL is, according to Cerasoli, Nicklin, and Ford (2014), far more intrinsically motivating. In many respects, PBL is considered an instrumental method that engages students in inquiry-based circumstances through authentic problems that have a real-world sense of relevance (Pecore, 2012) since students (prospective teachers) themselves have a stake in their outcomes (Lehman, George, Buchanan, \& Rush, 2006; Major \& Mulvihill, 2018).

The PBL model under discussion in this paper is in fact a hybrid model that recognizes the variability of the strategies that may be incorporated in such constructivist approaches (see, for example, Dahlgren \& Obers, 2001; Pawson et al., 2006). Hence, this hybrid PBL model is considered flexible and can be used across various disciplines and contexts (Kivela \& Kivela, 2005). In the hybrid model used in the teacher education course that is presented in this paper, lectures are included in the curricula and are aligned to the small group PBL tutorials. The model requires students' critical reflections on their own experiences (Barrows \& Tamblyn, 1980), their application of the knowledge to practical and authentic contexts (DeHaan, 2005), and the ability to communicate their observations and findings in interactive peer groups (Vygotsky, 1978). Course instructors can allow students to assume responsibility to arrive at their own final reflections (see, for example, Srinivasan et al., 2007). This approach is in line with McPhail (2018) who concluded that the focus of educational discourse has shifted from knowledge content towards process. In turn, providing prospective teachers with opportunities to engage in interprofessional dialogue can,

Provide an understanding of some of the knowledge (group functioning, roles and responsibilities of different professionals), skills (communication unreflective practice, leadership) and attitudes (mutual respect, willingness to collaborate, openness to trust) that should be learned. Clear competencies or learner outcomes are necessary for the development of formalized teaching innovations at both pre-licensure and post-licensure levels. (D'Amour \& Oandasan, 2005, p. 14)

Consistent with more traditional PBL environments, the model under study requires prospective teachers to integrate theory and practice in the process of investigating the respective dilemmas (Moallem, Hung, \& Dabbagh, 2019; Ritchey, 2013; Savery, 2015). Unlike case-based models of instruction, though, the PBL format implemented in this particular course does not require the prospective teacher participants to complete any preparation before reading the problem. Further, dataseeking is allowed so that students can identify the gaps in their learning during the small-group tutorial sessions. Last, and also unlike case-based models, the learning objectives and tasks are identified by the prospective teacher participants during the PBL group work and not determined before the group work begins (Daher, Jeet Singh, \& Kutty, 2017). 


\section{Contextual Framework}

The hybrid Problem-Based Learning model is offered as part of a mandatory third-year course in a concurrent teacher education program in a university in Ontario, Canada. The student-participants are studying in the Intermediate/Senior program (qualifying them as grade seven to twelve teachers). Their participation in the research study is optional. There are typically between 80 and 125 students enrolled in the course. In its inception in 2005, the course was entirely lecture-based. Through the process of redeveloping the course of study over a decade ago, the decision was made to incorporate more studentdriven instruction to better engage students in meaningful and authentic learning environments (Cherubini, 2017b). As the course evolved, it was clear that prospective teachers benefitted from an interactive learning model that provided them with opportunities to participate in rich discussion with peers, investigate the theory presented in the research as it applies to their unique learning needs, and integrate their knowledge and skills in a manner that fostered their own metacognitive awareness. While the emphasis on the current course is placed on the PBL process, various lecture topics are dispersed throughout the twelve (three-hour) sessions to present, among other topics, the Ontario College of Teacher's (OCT) Standards of Professional Practice and Ethical Standards of Practice (see Appendix 1). The OCT is the governing body of the teaching profession in Ontario. The Standards of Professional Practice and the Ethical Standards of Practice present clear implications on all fifteen of the dilemmabased cases in the textbook and hence the time spent on them in lecture is well justified.

The sequential steps of the unique Problem-Based Learning model are important to identify. The following steps are cited directly from the textbook (Cherubini, 2017b) and include:

Step One: Students individually read the case.

Step Two: On the respective Note page, students document what they perceive to be the most important concepts and/or ideas associated to the case description. Students are reminded that there should be minimal attention to grammar, spelling, and syntax; instead, the focus should reflect a 'stream of consciousness' approach to writing. It is imperative that students do not engage in discussion with peers, nor do they allow for an extended time to elapse between the reading of the case and their making notes.

Step Three: In the small-group cohorts [consisting of 4 to 6 members], each student will share their reflection with the rest of the group. During the sharing circle, students are encouraged to consider how value systems and ontological knowledge influence perceptions. After each student-presentation, the other members of the cohort will offer a response to the student reflections. In this manner, critical reflection is seen to be relational; in other words, individual and collective reflection is founded upon those subjects that matter most to prospective teachers. In this small-group cohort students are encouraged to integrate their perspectives and engage in broader conversations. Students will record and summarize the responses of their peers on the page provided.

Step Four: Each student in the group will share the case circumstances with a different professional educator. They have the flexibility of seeking the insights of a practicing teacher, department chair or division leader, school administrator, school board consultant, and/or senior school board administrator. Students are at liberty to either allow the educator to read the case for themselves or may in the interest of time provide a detailed synopsis of the case circumstances for them. Subsequently, students (and not the invited participant) are to document the thoughts of the educator on the respective page. Students are strongly encouraged to first allow the educational expert to express their opinions and perspectives into the case, before engaging in further discussion and dialogue about either the case circumstances or the expressed opinions. It is imperative that students record both the educator's perspectives and provide a succinct and concise summary of all discussion that ensued.

Step Five: Each student in the group will solicit the expert opinion of a professional who is not an educator (students will not consult with the same expert). Following the principles of interprofessional education, students are to invite a related professional in a field outside of education to share their thoughts on the case circumstances. Students will determine which interprofessional expert is best suited to offer critical insight into the case circumstances. Like 
Step Three, students are at liberty to either allow the interprofessional expert to read the case for themselves or may in the interest of time provide a detailed synopsis of the case circumstances for them. Subsequently, students (and not the interprofessional expert) are to document the thoughts of the expert on the respective page provided. Students are strongly encouraged to first allow the interprofessional expert to express their opinions and perspectives into the case before engaging in further discussion and dialogue about either the case circumstances or the expressed opinions. It is imperative that students record both the expert's perspectives and provide a succinct and concise summary of all discussion that ensued. Step Six: Students are to solicit the opinion of a parent/caregiver of a school-aged student relatively close in age to the case-based student. In this way, they have the flexibility of seeking the views of a parent/caregiver whom they believe would have an insightful opinion on the case. Students will not consult the same parent/caregiver. Students are at liberty to either allow the parent/caregiver to read the case for themselves or may in the interest of time provide a detailed synopsis of the case circumstances for them. Subsequently, students (and not the invited participant) are to document the thoughts of the parent/caregiver on the respective page. Students are strongly encouraged to first allow the parent/caregiver to express their opinions and perspectives into the case before engaging in further discussion and dialogue about either the case circumstances or the expressed opinions. It is imperative that students record both the parent/caregiver perspectives and provide a succinct and concise summary of all discussion that ensues.

Step Seven: At this point, students have the benefit of bringing the discourse of research into the conversations. Students will research [two] peer-reviewed academic journals that they individually determine to be most relevant to shift the reflection from a personal and professional tone to more of a theoretical and academic one. This is not meant to be a grouptask. Each individual student will investigate the literature that they individually deem to be relevant to the issues that resonate most with them. Students will delve into the related literature to re-engage their critical reflection. By consulting with the relevant research, students are invited to re-orient their ontological perspectives, and preside further over the central tensions that are contested in each problem. Students will provide a summary of each research article, and more significantly, evaluate how the article has made a statement to the specific developments of the problem under examination.

Step Eight: Consider the concepts of thinking and reflection, (prospective) teacher identity, Professional Standards and social justice, becoming a teacher, critical consciousness and conceptual spaces. Discuss the implications that emerge [from these concepts] in the context of your reflections. In addition, the following may also be considered in your reflections:

(1) How would you have felt and/or perceived the case-experience as a secondary school student?

(2) How are your feelings and/or perceptions the same or different currently as a prospective teacher?

(3) Discuss your reflections to the above questions in light of how you project your feelings and/or perceptions as a practising teacher.

Step Nine: Students return to the same small-group cohort to which they were originally assigned. In turn, students are afforded 5 to $7 \mathrm{~min}$. to share with the cohort the findings that they have determined to be of greatest significance. The sharing at this time is not meant to be either prescriptive or exhaustive; rather, students are at liberty to distinguish those concepts, be they structural or systemic, that represented the greatest significance. This step provides students in the group with a wealth of opinions, research, perspectives and evaluative statements. On the page provided, students will record the observations of their peers that they have determined as important to their own understanding of the case circumstances.

Step Ten: In the last step, students independently complete a final reflection on the pages provided in this book. The scope of the critical reflection is determined by the prospective teacher. It presumes that each student has benefited from the enabling environment and process of this instructional model. The final reflection represents an ordering of experience, perception, and critical thought that depicts in its own unique manner how students have negotiated the perplexities of the inquiry under investigation. The final and cumulative 
reflection is an opportunity for prospective teachers to communicate their innate awareness of the underlying issues, the conceptual connections, and the philosophical threads woven throughout the research that have been integral to their understanding of the circumstances.

While it is not within the scope of this paper to discuss the assessment and evaluation of prospective teacher participants during the PBL process, it will suffice to state that the instructor collects students' responses to the problem at the mid-way point and near the final class of the semester. Students submit their work (including their notes from all the respective steps) in a portfolio and are informed at the beginning of the course that their Final Reflections represent the culmination of their thinking for each inquiry.

\section{Discussion}

The hybrid Problem-Based Learning model under discussion is instrumental in terms of providing prospective teachers with opportunities to integrate and apply their learning. Unlike traditional lectures that can position students as passive learners, this hybrid PBL model not only elicits students' prior knowledge acquired in previous coursework, but also situates them as active learners that embrace a problem and engage in an inquiry process whereby they take responsibility to acquire, organize, and implement new and relevant learning as it applies to the problem under study. Consequently, the model requires prospective teachers to engage meaningfully in the process of inquiry that, in turn, creates the spaces for them to examine, discuss, and make sense of the complexities and perspectives of teachers' responsibilities and expectations.

The hybrid PBL model provides a framework for a systematic approach to inquiry-based learning. By situating students at the core of their learning, this PBL model promotes a clearer understanding of content knowledge. Prospective teachers are required to give elaborate attention to the density of each dilemma, develop an awareness of any gaps in their knowledge, and become increasingly capable of recognizing and appreciating the reciprocal nature of their learning in peer-to-peer relations. The process involves their discerning both the importance and application of a concept to the inquiry (Virtue \& Hinnant-Crawford, 2019). The result is not only a heightened recognition of the metacognitive process they use to arrive at such discernment, but a greater ability to engage in deep learning (Huberman, Bitter, Anthony, \& O'Day, 2014). For these researchers, deep learning is "an ability to apply [that] understanding to novel problems and situations, and a range of competencies related to human interaction and self-management" (Huberman et al., 2014, p. 1). The deep learning emerges in the conceptual spaces where prospective teachers, both individually and collectively, consolidate the information gathered throughout the inquiry process - including any preconceived assumptions and biases they may have had that contribute to what can often be their overwhelming uneasiness toward a viable solution. Metacognitively, the PBL model facilitates opportunities for prospective teachers to first negotiate the ambiguities and complexities when the Ontario College of Teacher's Professional and Ethical Standards are imposed on the inquiry conversations, and second, gain some definitive perspective about their own difficulties in arriving at possible responses to the case-based dilemma.

While prospective teachers do not necessarily have the actual experience as it relates to the problem in each case, the process requires them to reflect critically on the impact of the circumstances on the respective case subjects, including students, teachers, administrators, parents, and/or the school community. Throughout the inquiry process prospective teachers gather the relevant information, discuss the progression of their thoughts, and re-evaluate their original inferences. Using supporting details from an expert perspective or journal article, prospective teachers participate in critical peer discussions to detect inconsistences, identify competing motives of case-subjects, and seek clarification to their own learning. The process of continually challenging their own and others' interpretation exercises very important elaboration and inferencing skills. Participants can invest additional time and energy on those steps (as previously outlined) that require more attention (see Son \& Kornell, 2009). Important to the process, as various trials in the redevelopment of the course have attested to, is structuring the necessary time for prospective teachers to engage thoughtfully in the details of the problem and discuss extensively the related implications (Vardi \& Ciccarelli, 2008). Time must be allocated for prospective teachers to both co-construct possible solutions and consider multiple outcomes in dynamic peer-to-peer interactions (Barber \& Kin, 2016). For Kearney et al. (2012), it is especially important that participants 
develop conducive social networks that contribute to social and personal learning processes. This includes providing prospective teacher participants with the option of using on-line communication to complement the time provided in-class for tutorial group work. The groups that are especially successful tend to organize a virtual page or forum that is exclusive to their tutorial where they can exchange information and sustain their conversations outside of class time. The members of each tutorial group need to feel comfortable enough to express their perspectives openly and candidly in real and virtual collaborative learning environments that encourage constructive and critical feedback (Littlejohn, Beetham, \& McGill, 2012). Students need to be willing to share and discuss the successes and difficulties of the inquiry process as they approach and investigate each problem. If participants feel threatened by expressing their views, then the process can be quite alienating. The instructor, therefore, must make a conscious effort to address the significance of respectful group relations that encourage discussion in an inclusive and safe learning environment.

Also noteworthy to this discussion of creating enabling spaces for prospective teachers to engage in a PBL environment is the fact that such opportunities may also contribute to the formation of teacher identities (see Mulcahy, 2006). Mulcahy describes the ontological perspective that aligns with PBL, and specifically with the hybrid model being presented. The process of,

Learning to teach through problem-based learning entails practices that recruit, challenge and create identity. In process- and problem-based pedagogies, conditions are created for various and contesting constructions of the self. Central to these constructions are the spaces in which (and across and through which) these new identities form. Identities and spatialities intertwine and interact. (Mulcahy, 2006, p. 57)

Hence, prospective teachers are affected by their own experiences in the process of PBL. By considering their viewpoints in a variety of rich contexts, prospective teacher participants can thoughtfully process the meaning behind each of their contributions. They have opportunities to selfreflect on prior learning and past experiences while speculating on other possibilities and interpretations to each problem. They must be willing to demonstrate a degree of relative transparency to their thinking process as their sense of self takes root in the viable responses to the respective inquiries. In the process, prospective teachers experience growing confidence in their ability to make meaningful contributions to the group's conversations. In this manner, participants develop a sense of identity whereby they respect the value of their thoughts and interpretations as prospective teachers. The attitudinal component towards the formation of their prospective teacher identity is clear. While such an identity formation is fluid, the more exposure prospective teachers have to make comparisons, direct their investigations, distinguish fact and opinion, and incorporate supporting details, the more their sense of self as an emerging professional becomes embedded. Prospective teachers can trace the development of the progression of their constructions of self by reflecting upon the changes in their learning in those unique spaces where their social agency is exercised, and knowledge is co-created with peers.

\section{Conclusion}

Problem-Based Learning is an effective instructional strategy for teacher education. Its student-centred and social constructivist approach is especially conducive to prospective teachers' active involvement in inquiry-based learning (Erdogan \& Senemoglu, 2013). In addition, the unique hybrid PBL model discussed in this paper presents prospective teachers with cognitive and affective dimensions of engagement. The complex discourses that ensue in the PBL tutorial groups cultivate a sense of deep learning in prospective teachers where they can apply new knowledge to difficult situations across a range of competencies. Further, the PBL model facilitates a sense of identity-formation as participants make informed and substantial contributions to discourses that increases their confidence and strengthens their voice as prospective teachers.

The experiences in this hybrid PBL environment provides prospective teachers with a sense of ownership over their learning and opportunities to confirm their understanding of various theoretical and practice-based concepts. Meaning is created in those spaces and emerges from constructive, collaborative, and critical dialogue amongst peers. 


\section{References}

1. Anderson, J. R. (2005). Cognitive psychology and its implications. Macmillan.

2. Assen, J. H. E., Meijers, F., Otting, H., \& Poell, R. F. (2016). Explaining discrepancies between teacher beliefs and teacher interventions in a problem-based learning environment: A mixed methods study. Teaching and teacher education, 60, 12-23.

3. Ball Loewenberg, D., \& Forzani, F. M. (2009). The work of teaching and the challenge for teacher education. Journal of teacher education, 60(5), 497-511.

4. Barber, W., \& King, S. (2016). Teacher-Student Perspectives of Invisible Pedagogy: New Directions in Online Problem-Based Learning Environments. Electronic Journal of e-Learning, 14(4), 235-243.

5. Barrett, T. (2010). The problem-based learning process as finding and being in flow. Innovations in Education and Teaching international, 47(2), 165-174.

6. Barrows, H. S. (1996). Problem-based learning in medicine and beyond: A brief overview. New directions for teaching and learning, 1996(68), 3-12.

7. Barrows, H. S., \& Tamblyn, R. M. (1980). Problem-based learning: An approach to medical education. Springer Publishing Company.

8. Borko, H., Peressini, D., Romagnano, L., Knuth, E., Willis-Yorker, C., Wooley, C., ... \& Masarik, K. (2000). Teacher education does matter: A situative view of learning to teach secondary mathematics. Educational Psychologist, 35(3), 193-206.

9. Bridges, S., McGrath, C., \& Whitehill, T. L. (Eds.). (2012). Problem-based learning in clinical education: The next generation (Vol. 8). Springer Science \& Business Media.

10. Cerasoli, C. P., Nicklin, J. M., \& Ford, M. T. (2014). Intrinsic motivation and extrinsic incentives jointly predict performance: A 40-year meta-analysis. Psychological bulletin, 140(4), 980.

11. Cherubini, L. (2009). Exploring prospective teachers' critical thinking: Case-based pedagogy and the standards of professional practice. Teaching and Teacher Education, 25(2), 228-234.

12. Cherubini, L. (2017a). Situating Thinking and Reflection: Studying Teaching and Learning. Welland, ON: Soleil Publishing. ISBN: 978-894935-98-2.

13. Cherubini, L. (2017b). Case Study Inquiry Seminars: A Research-to-Practice Model. (Second Edition). Welland, ON: Soleil Publishing. ISBN: 978-1-894935-97-5.

14. Daher, A. M., Singh, H. J., \& Kutty, M. K. (2017). Differentiating case-based learning from problem-based learning after a two-day introductory workshop on case-based learning. Australasian Medical Journal (Online), 10(12), 973-980.

15. Dahlgren, M. A., \& Öberg, G. (2001). Questioning to learn and learning to question: Structure and function of problem-based learning scenarios in environmental science education. Higher education, 41(3), 263-282.

16. D'Amour, D., \& Onadasan, I. (2005). Interprofessionality as the field of interprofessional practice and interprofessional education: An emerging concept. Journal of Interprofessional Care, 19 (Suppl. 1), 8 - 20.

17. DeHaan, R. L. (2005). The impending revolution in undergraduate science education. Journal of Science Education and Technology, $14(2), 253-269$.

18. Erdogan, T., \& Senemoglu, N. (2014). Problem-based learning in teacher education: Its promises and challenges. Procedia-Social and Behavioral Sciences, 116(21), 459-463.

19. Filipenko, M., \& Naslund, J. A. (Eds.). (2016). Problem-based learning in teacher education. Switzerland: Springer.

20. Golightly, A., \& Raath, S. (2015). Problem-based learning to foster deep learning in preservice geography teacher education. Journal of Geography, 114(2), 58-68.

21. Goodnough, K. (2005). Issues in modified problem-based learning: A self-study in pre-service science-teacher education. Canadian Journal of Science, Mathematics and Technology Education, 5(3), 289-306.

22. Grigg, R., \& Lewis, H. (2018). Moving the andragogy of teacher educators forward: the potential and challenges of Problem-Based Learning in teacher education. Journal of Problem-Based Learning, 5(1), 5-20.

23. Henderson, R. (2016). (Ed.) Problem-based learning: Perspectives, methods and challenges. Nova Science Publishers.

24. Huberman, M., Bitter, C., Anthony, J., \& O'Day, J. (2014). The Shape of Deeper Learning: Strategies, Structures, and Cultures in Deeper Learning Network High Schools. Findings from the Study of Deeper Learning Opportunities and Outcomes: Report 1. American Institutes for Research. 
25. Hung, W. (2009). The 9-step problem design process for problem-based learning: Application of the 3C3R model. Educational Research Review, 4(2), 118-141.

26. Ice, P., Gibson, A. M., Boston, W., \& Becher, D. (2011). An exploration of differences between community of inquiry indicators in low and high disenrollment online courses. Journal of Asynchronous Learning Networks, 15(2), 44-69.

27. Kearney, M., Schuck, S., Burden, K., \& Aubusson, P. (2012). Viewing mobile learning from a pedagogical perspective. Alt-J-Research In Learning Technology, 20(1).

28. Kivela, J., \& Kivela, R. J. (2005). Student perceptions of an embedded problem-based learning instructional approach in a hospitality undergraduate program. International Journal of Hospitality Management, 24(3), 437464.

29. Lehman, J. D., George, M., Buchanan, P., \& Rush, M. (2006). Preparing teachers to use problem-centered, inquiry-based science: Lessons from a four-year professional development project. Interdisciplinary Journal of Problem-Based Learning, 1(1), 7.

30. Littlejohn, A., Beetham, H., \& McGill, L. (2012). Learning at the digital frontier: a review of digital literacies in theory and practice. Journal of computer assisted learning, 28(6), 547-556.

31. Major, T., \& Thalia, M. (2018). Problem-based learning pedagogies in teacher education: The case of Botswana. Interdisciplinary journal of problem-based learning, 12(1), 1.

32. McPhail, G. (2018). Curriculum integration in the senior secondary school: A case study in a national assessment context. Journal of Curriculum Studies, 50(1), 56-76.

33. McPhee, A. D. (2009). Problem-based learning in initial teacher education: taking the agenda forward. The Journal of Educational Enquiry, 3(1).

34. Moallem, M., Hung, W., \& Dabbagh, N. (Eds.). (2019). The Wiley handbook of problem-based learning. Wiley Blackwell.

35. Mulcahy, D. (2006). The salience of space for pedagogy and identity in teacher education: problem-based learning as a case in point. Pedagogy, Culture $\&$ Society, 14(01), 55-69.

36. Nousiainen, T., Kangas, M., Rikala, J., \& Vesisenaho, M. (2018). Teacher competencies in game-based pedagogy. Teaching and Teacher Education, 74, 85-97.

37. Pang, J. (2011). Case-based pedagogy for prospective teachers to learn how to teach elementary mathematics in Korea. $Z D M, 43(6-7), 777-789$.

38. Pawson, E., Fournier, E., Haigh, M., Muniz, O., Trafford, J., \& Vajoczki, S. (2006). Problem-based learning in geography: Towards a critical assessment of its purposes, benefits and risks. Journal of Geography in Higher Education, 30(1), 103-116.

39. Pecore, J. L. (2013). Beyond beliefs: Teachers adapting problem-based learning to preexisting systems of practice. Interdisciplinary Journal of Problem-Based Learning, 7(2), 1.

40. Pourshafie, T., \& Murray-Harvey, R. (2013). Facilitating problem-based learning in teacher education: Getting the challenge right. Journal of Education for Teaching, 39(2), 169-180.

41. Ritchey, T. (2011). Wicked problems-social messes: Decision support modelling with morphological analysis (Vol. 17). Springer Science \& Business Media.

42. Ruiz-Gallardo, J. R., González-Geraldo, J. L., \& Castaño, S. (2016). What are our students doing? Workload, time allocation and time management in PBL instruction. A case study in Science Education. Teaching and Teacher Education, 53, 51-62.

43. Santagata, R., \& Guarino, J. (2011). Using video to teach future teachers to learn from teaching. $Z d m$, 43(1), 133-145.

44. Savery, J. R. (2015). Overview of problem-based learning: Definitions and distinctions. Essential readings in problem-based learning: Exploring and extending the legacy of Howard S. Barrows, 9, 5-15.

45. Savin-Baden, M. (2007). Challenging models and perspectives of problem-based learning. In Management of change (pp. 9-29). Brill Sense.

46. Shulman, L. S., \& Wilson, S. M. (2004). The wisdom of practice: Essays on teaching, learning, and learning to teach (Vol. 8). Jossey-Bass Inc Pub.

47. Son, L. K., \& Kornell, N. (2009). Simultaneous decisions at study: Time allocation, ordering, and spacing. Metacognition and Learning, 4(3), 237-248.

48. Srinivasan, M., Wilkes, M., Stevenson, F., Nguyen, T., \& Slavin, S. (2007). Comparing problem-based learning with case-based learning: effects of a major curricular shift at two institutions. Academic Medicine, 82(1), 74-82. 
49. Steele, M. D. (2008). Building bridges: Cases as catalysts for the integration of mathematical and pedagogical knowledge. Cases in mathematics teacher education: Tools for developing knowledge needed for teaching, 4, 5772.

50. Vardi, I., \& Ciccarelli, M. (2008). Overcoming problems in problem-based learning: a trial of strategies in an undergraduate unit. Innovations in Education and Teaching International, 45(4), 345-354.

51. Virtue, E. E., \& Hinnant-Crawford, B. N. (2019). "We're doing things that are meaningful": Student Perspectives of Project-based Learning Across the Disciplines. Interdisciplinary Journal of Problem-Based Learning, 13(2).

52. Vygotsky, L. S. (1978). Mind in society: The development of higher mental processes (E. Rice, Ed. \& Trans.). F. Smith and M. S. Waterman (1981), "Identification of common molecular subsequences," Journal of molecular biology, vol. 147, no. 1, pp. 195-197.

\section{Appendix}

\section{The Standards of Practice for the Teaching Profession are:}

Commitment to Students and Student Learning

Members are dedicated in their care and commitment to students. They treat students equitably and with respect and are sensitive to factors that influence individual student learning. Members facilitate the development of students as contributing citizens of Canadian society.

Professional Knowledge

Members strive to be current in their professional knowledge and recognize its relationship to practice. They understand and reflect on student development, learning theory, pedagogy, curriculum, ethics, educational research and related policies and legislation to inform professional judgment in practice.

Professional Practice

Members apply professional knowledge and experience to promote student learning. They use appropriate pedagogy, assessment and evaluation, resources and technology in planning for and responding to the needs of individual students and learning communities. Members refine their professional practice through ongoing inquiry, dialogue and reflection.

Leadership in Learning Communities

Members promote and participate in the creation of collaborative, safe and supportive learning communities. They recognize their shared responsibilities and their leadership roles in order to facilitate student success. Members maintain and uphold the principles of the ethical standards in these learning communities.

Ongoing Professional Learning

Members recognize that a commitment to ongoing professional learning is integral to effective practice and to student learning. Professional practice and self-directed learning are informed by experience, research, collaboration and knowledge.

(as cited in:

https://www.oct.ca/public/professional-standards/standards-of-practice)

\section{The Ethical Standards for the Teaching Profession are:}

Care

The ethical standard of Care includes compassion, acceptance, interest and insight for developing students' potential. Members express their commitment to students' well-being and learning through positive influence, professional judgment and empathy in practice.

Respect

Intrinsic to the ethical standard of Respect are trust and fair-mindedness. Members honour human dignity, emotional wellness and cognitive development. In their professional practice, they model respect for spiritual and cultural values, social justice, confidentiality, freedom, democracy and the environment.

Trust 
The ethical standard of Trust embodies fairness, openness and honesty. Members' professional relationships with students, colleagues, parents, guardians and the public are based on trust.

Integrity

Honesty, reliability and moral action are embodied in the ethical standard of Integrity. Continual reflection assists members in exercising integrity in their professional commitments and responsibilities.

(as cited in:

https://www.oct.ca/public/professional-standards/ethical-standards) 